\title{
In-vitro induction of capacitation of fresh and frozen spermatozoa of the Siberian tiger (Panthera tigris)
}

\author{
A. P. Byers*, A. G. Hunter*, U. S. Seal†, G. A. Binczik $\$$, E. F. Graham*, \\ N. J. Reindl $\ddagger$ and R. L. Tilson $\ddagger$ \\ * Department of Animal Science, University of Minnesota, St Paul, MN 55108, USA; \\ $\dagger V A$ Medical Center, Minneapolis, MN 55417, USA; and $\ddagger$ Minnesota Zoological Garden, \\ Apple Valley, MN 55124, USA
}

\begin{abstract}
Summary. Electroejaculates from 5 tigers were split and half of each was assayed fresh while the remainder was frozen and thawed before being assayed. Preincubation time, temperature and removal of seminal plasma were evaluated for their effect on in-vitro capacitation. Ability of spermatozoa to penetrate oocytes, as measured by the zonafree hamster egg-sperm penetration assay (SPA), was used as verification of capacitation. Results of the experiments with fresh semen indicate that: (1) preincubation time affects the fertilizability of tiger spermatozoa with $2 \mathrm{~h}$ appearing optimal, (2) a preincubation temperature of $37^{\circ} \mathrm{C}$ results in significantly higher penetration rates than does a $22^{\circ} \mathrm{C}$ treatment, and (3) tiger seminal plasma does not appear to contain decapacitation factors, as has been reported for several other species. Frozen semen experiments indicate that (1) frozen-thawed tiger spermatozoa must be removed from the environment of the semen extender before capacitation can take place, and (2) the freeze-thaw procedure results in a shortening of the required capacitation time.
\end{abstract}

Keywords: capacitation; Siberian tiger; spermatozoa; cryopreservation

\section{Introduction}

As wild populations of exotic felids decline, the need for captive management programmes and reproductive research increases. The goal of a captive management programme is not just to increase the number of individuals in existence, but also to establish and maintain a stable, genetically diverse population in captivity and in the wild (Seal \& Foose, 1983). An understanding of basic gamete physiology is imperative for development of the reproductive technology necessary for survival and propagation of these endangered species.

Capacitation is a biochemical process that occurs on the sperm cell surface which enables the spermatozoon to undergo the acrosome reaction before fertilization (Austin, 1952). A preincubation interval of at least $30 \mathrm{~min}$ is required for domestic cat spermatozoa to capacitate and thus acquire the ability to penetrate oocytes in vitro (Hamner et al., 1970; Niwa et al., 1985). Bowen (1977) reported that no capacitation time was required for spermatozoa from the ductus deferens of the cat to penetrate cat oocytes. However, in that study ova were co-incubated with spermatozoa for $12-14 \mathrm{~h}$ before being evaluated for fertilization.

The zona-free hamster egg sperm penetration assay (SPA) indirectly measures capacitation by measuring the ability of spermatozoa to penetrate zona pellucida-free hamster oocytes (Rogers et al., 1979). Siberian tiger spermatozoa are capable of penetrating zona-free hamster eggs (Byers et al., 1987). The SPA is presently the best in-vitro test available to provide information about the functional capacity of spermatozoa (Yanagimachi, 1984). The experiments reported here were 
designed, in part, to determine more precisely the conditions required for in-vitro capacitation of fresh and frozen Siberian tiger spermatozoa as verified by the SPA.

\section{Materials and Methods}

Animals and semen collection. Five Siberian tigers (Panthera tigris) were used in this study. Three of the animals are housed at the Minnesota Zoological Garden (Apple Valley, MN) and are of proven fertility. The other two tigers are from the Como Zoo (St Paul, MN): they are both just over 2 years old and have not been used in a breeding programme. Animals were anaesthetized with ketamine, xylazine and diazepam administered by blow dart. Semen was collected once a week by electroejaculation according to the method described by Howard et al. (1984a) with the following modifications. A Teflon rectal probe with a diameter of $3.8 \mathrm{~cm}$ containing three longitudinal $14.6-\mathrm{cm}$ stainless-steel electrodes spaced $0.5 \mathrm{~cm}$ apart was lubricated and inserted approximately $27 \mathrm{~cm}$ into the tiger's rectum. The probe was positioned so that the electrodes were orientated ventrally. An ejaculation sequence consisted of 80 pulses given in 4 series: each series of 20 pulses was given at $5-\mathrm{V}$ increments from 25 to 40 volts with a range of $25-400 \mathrm{~mA}$. Two ejaculates from each animal were obtained in separate, warmed plastic tubes, $10 \mathrm{~min}$ apart on each collection day.

The samples were transported to the laboratory at $37^{\circ} \mathrm{C}$ and a semen analysis was immediately performed. Each ejaculate was transferred to a graduated conical centrifuge tube and its volume was recorded. Sperm cell concentration was recorded using a haemocytometer. A drop of the sample was placed on a slide and covered with a coverslip for estimation of progressive motility by phase contrast microscopy. A smear was stained with eosin and nigrosin and evaluated for sperm viability (live/dead) (Swanson \& Bearden, 1951). Morphology was considered normal for cells with single, oval heads, straight attached tails and lacking cytoplasmic droplets. Acrosome status was assessed on sperm smears using naphthol yellow and erythrosin B stains (Lenz et al., 1983).

Daily, the two ejaculates from each individual animal were pooled. Half of each pooled sample was assayed fresh and the remainder was frozen (see below) for assessment after thawing. Preincubation time, temperature and removal of seminal plasma were evaluated for their effect on in-vitro capacitation. The frozen-thawed samples were used to evaluate the effect of preincubation time and the removal of semen extender on sperm penetration rates.

Hamster egg-sperm penetration assay. This assay was a modification of the method of Yanagimachi et al. (1976). Immature golden hamsters were superovulated with 40 i.u. PMSG (Sigma, St Louis, MO, USA) injected i.p. and 40 i.u. hCG (Sigma) $55 \mathrm{~h}$ later. At $17 \mathrm{~h}$ after hCG the animals were killed, oocytes harvested and zona-free oocytes prepared as described by Byers $e$ t al. (1987). The zona-free eggs were then washed 3 times and 20 eggs were added to each $50 \mu \mathrm{l}$ droplet of spermatozoa (prepared as described below for each experiment) under mineral oil. The ova and spermatozoa were co-incubated at $37^{\circ} \mathrm{C}$ in an atmosphere of $5 \% \mathrm{CO}_{2}$ in air for $3 \mathrm{~h}$. After this time the ova were removed from the drops, placed on a slide and flattened with a coverslip. The zona-free hamster oocytes were examined by phase contrast microscopy at $\times \mathbf{4 0 0}$ magnification. The presence of a swollen sperm head with its dissociated tail, and/or a male pronucleus in the cytoplasm indicated ovum penetration.

Freeze-thaw procedure. Each $5 \mathrm{ml}$ semen sample was transferred to a conical centrifuge tube and centrifuged at $\sim 120 \mathrm{~g}$ for $10 \mathrm{~min}$, forming a very soft sperm cell pellet. Seminal plasma was removed and $0.5 \mathrm{ml}$ TEST-yolk extender (Graham et al., 1972) with $7.5 \%$ glycerol $(325 \mathrm{mosmol} / \mathrm{kg}, \mathrm{pH} 7)$ was added dropwise. The sample was then cooled to $5^{\circ} \mathrm{C}$ over $3 \mathrm{~h}$ in a $150-\mathrm{ml}$ beaker containing $60 \mathrm{ml}$ water. Samples were loaded into $0.25-\mathrm{ml}$ French straws and frozen in a controlled freezer (Cryogenic, Minnesota Valley Engineering, New Prague, MN, USA) at a rate of $-3^{\circ} \mathrm{C} / \mathrm{min}$ to $-40^{\circ} \mathrm{C}$ and then at $-20^{\circ} \mathrm{C} / \mathrm{min}$ to $-100^{\circ} \mathrm{C}$. When the temperature reached $-100^{\circ} \mathrm{C}$ the straws were transferred to a liquid nitrogen storage tank where they remained for a period of not less than 1 week.

Straws of semen were removed from liquid nitrogen and thawed immediately in a $37^{\circ} \mathrm{C}$ waterbath for $15 \mathrm{sec}$. Contents of the straws were transferred to $15-\mathrm{ml}$ centrifuge tubes which were held in a $37^{\circ} \mathrm{C}$ waterbath during dilution. Samples $\left(100 \mu \mathrm{l}\right.$ ) of Medium BWW (Biggers et al., 1971), pH 7.5 (equilibrated in a $\mathrm{CO}_{2}$ incubator at $37^{\circ} \mathrm{C}$ ), were added at 1 -min intervals, gently mixing after each addition to a volume of $500 \mu \mathrm{l}$. Samples $(200 \mu \mathrm{l})$ were then added at $30-\mathrm{sec}$ intervals to a volume of $1.5 \mathrm{ml}$. An additional $1.5 \mathrm{ml}$ Medium BWW was added, giving a final volume of $3.0 \mathrm{ml}$.

Experiment 1. Spermatozoa were washed once in an equal volume of Medium BWW, $\mathrm{pH} 7 \cdot 5$, and centrifuged at $400 \mathrm{~g}$ for $5 \mathrm{~min}$ at room temperature. The supernatant was discarded and the pellet resuspended to a concentration of $25 \times 10^{6}$ spermatozoa $/ \mathrm{ml}$ in fresh medium. An aliquant of the sperm suspension was removed at this time to serve as the $0 \mathrm{~h}$ sample while the remainder was incubated at $37^{\circ} \mathrm{C}$ in an atmosphere of $5 \% \mathrm{CO}_{2}$ in air for $1,2,3$ or $4 \mathrm{~h}$ before use in the SPA.

Experiment 2. Approximately $6 \mathrm{ml}$ semen was split into two tubes; the spermatozoa were washed in Medium BWW as described above and resuspended to $25 \times 10^{6}$ spermatozoa/ml. One tube was incubated for $2 \mathrm{~h}$ at $37^{\circ} \mathrm{C}$ while the other was held at room temperature $\left(22^{\circ} \mathrm{C}\right)$ for $2 \mathrm{~h}$. After preincubation, spermatozoa from each treatment were used in the SPA. 
Experiment 3. Semen was divided into 2 samples, one was washed and resuspended as described, while the other was centrifuged at $400 \mathrm{~g}$ for $5 \mathrm{~min}$ at room temperature but resuspended to the same concentration of $25 \times 10^{6}$ spermatozoa $/ \mathrm{ml}$ in its seminal plasma. Both samples were preincubated at $37^{\circ} \mathrm{C}$ for $2 \mathrm{~h}$ before use in the SPA.

Experiment 4. Frozen-thawed spermatozoa were removed from straws, diluted dropwise to $3 \mathrm{ml}$ with Medium BWW as described previously, centrifuged at $400 \mathrm{~g}$ for $5 \mathrm{~min}$, and resuspended in Medium BWW to a concentration of $10 \times 10^{6}$ spermatozoa $/ \mathrm{ml}$. An aliquant was used immediately in the SPA while the remainder was incubated in a $5 \% \mathrm{CO}_{2}$ atmosphere for $2 \mathrm{~h}$ at $37^{\circ} \mathrm{C}$ before use in the assay.

Experiment 5. The contents of the thawed straws were transferred to conical centrifuge tubes and diluted dropwise with Medium BWW allowing for equilibration between drops. The sperm suspension was either used in this diluted state (unwashed) or centrifuged at $400 \mathrm{~g}$ for $5 \mathrm{~min}$ and resuspended in fresh Medium BWW to remove the extender (washed). Neither sample was preincubated before use in the SPA. A final concentration of $10 \times 10^{6}$ spermatozoa $/ \mathrm{ml}$ was used for each treatment in this experiment. Eight replicates were run using 229 zona-free hamster oocytes.

Experiment 6. Data obtained from assays of freshly ejaculated spermatozoa coincubated for $2 \mathrm{~h}$ at $37^{\circ} \mathrm{C}$ before use in the SPA were compared to penetration rates of spermatozoa which had been frozen-thawed, removed from semen extender and used immediately in the SPA. In addition, a comparison was made of penetration rates by fresh and frozen-thawed spermatozoa from the same ejaculate.

Statistics. Penetration results of Exps 1-5 were analysed using the $\chi^{2}$ test. This permits comparison within individual experiments and also takes into account variations in egg sample sizes. Differences were considered significant if $P<0.05$. Differences between percentage penetration by fresh and frozen spermatozoa were analysed using a $t$ test. To evaluate differences between penetration rates of fresh and frozen-thawed spermatozoa from the same ejaculate, a logit analysis was performed. Percentage acrosome reaction and percentage motility were compared using analysis of variance. Correlation coefficients were calculated for oocyte penetration rates $v s$ semen analysis parameters.

\section{Results}

The semen analyses are given in Table 1 . The means for measures evaluated fall within the ranges reported by Howard et al. (1984b) for Siberian tigers.

Table 1. Characteristics of Siberian tiger semen

\begin{tabular}{|c|c|c|c|c|c|c|}
\hline $\begin{array}{l}\text { Tiger } \\
\text { No. }\end{array}$ & $\begin{array}{c}\text { No. of } \\
\text { samples }\end{array}$ & $\begin{array}{l}\text { Volume } \\
\text { (ml) }\end{array}$ & $\begin{array}{c}\text { Conc. } \\
\left(\times 10^{-6} / \mathrm{ml}\right)\end{array}$ & $\begin{array}{c}\text { Motility } \\
(\%)\end{array}$ & $\begin{array}{l}\text { Viability } \\
\text { (\% live) }\end{array}$ & $\begin{array}{l}\text { Morphology } \\
\text { (\% normal) }\end{array}$ \\
\hline $\begin{array}{r}1159 \\
862 \\
2832 \\
105 \\
106\end{array}$ & $\begin{array}{r}17 \\
7 \\
8 \\
5 \\
4\end{array}$ & $\begin{array}{r}11.7 \pm 2.3 \\
11.8 \pm 6.9 \\
11.8 \pm 2.9 \\
8.7 \pm 1.9 \\
7.6 \pm 1.9\end{array}$ & $\begin{array}{r}80.6 \pm 44.5 \\
59.6 \pm 34.8 \\
21.9 \pm 11.7 \\
70.9 \pm 22.1 \\
6.6 \pm 4.9\end{array}$ & $\begin{array}{l}68.4 \pm 6.4 \\
62.1 \pm 9.5 \\
37.5 \pm 9.5 \\
67.5 \pm 15.0 \\
60.0 \pm 17.3\end{array}$ & $\begin{array}{l}66.8 \pm 6.6 \\
63.1 \pm 4.4 \\
41.8 \pm 7.5 \\
60.7 \pm 7.9 \\
54.0 \pm 21.4\end{array}$ & $\begin{array}{l}81 \cdot 5 \pm 3.7 \\
77 \cdot 0 \pm 4.5 \\
78.7 \pm 4.4 \\
83.2 \pm 2.3 \\
77.7 \pm 4.7\end{array}$ \\
\hline & & $10.8 \pm 3.4$ & $53 \cdot 3 \pm 47 \cdot 1$ & $60 \cdot 1 \pm 14 \cdot 7$ & $58.1 \pm 12.9$ & $78.2 \pm 7.4$ \\
\hline
\end{tabular}

Values are mean \pm s.e.m.

\section{Experiment 1: effect of preincubation time on fresh semen}

Preincubation time at $37^{\circ} \mathrm{C}$ affected $(P<0.005)$ the capacitation of the spermatozoa, with $2 \mathrm{~h}$ appearing to be optimal under our conditions $(P<0.025)$ (Table 2$)$. None of the 436 oocytes coincubated with $0 \mathrm{~h}$ spermatozoa (spermatozoa not preincubated before use in the SPA) were penetrated. Sperm motility showed a substantial decline over time, while there was no significant difference in percentage of acrosome-reacted spermatozoa. Whether these acrosome-reacted spermatozoa were the result of true acrosome reactions or were due to nonspecific degeneration of the acrosome is unknown.

\section{Experiment 2: effect of preincubation temperature on fresh semen}

Preincubation at $37^{\circ} \mathrm{C}$ for $2 \mathrm{~h}$ rendered tiger spermatozoa capable of penetrating zona-free hamster oocytes (Table 3) while preincubation at $22^{\circ} \mathrm{C}$ for $2 \mathrm{~h}$ did not. Spermatozoa held at $22^{\circ} \mathrm{C}$ 
Table 2. Effect of preincubation of Siberian tiger spermatozoa on sperm motility, acrosome status and ability to penetrate zona-free hamster oocytes

\begin{tabular}{|c|c|c|c|c|}
\hline \multirow[b]{2}{*}{$\begin{array}{l}\text { Time } \\
\text { (h) }\end{array}$} & \multirow[b]{2}{*}{$\begin{array}{l}\text { \% Motility } \\
\text { (replicates) }\end{array}$} & \multirow{2}{*}{$\begin{array}{l}\% \text { Acrosome- } \\
\text { reacted } \\
\text { (replicates) }\end{array}$} & \multicolumn{2}{|c|}{ Penetration } \\
\hline & & & $\begin{array}{l}\text { No. penetrated/ } \\
\text { no. evaluated }\end{array}$ & $\begin{array}{l}\% \pm \text { s.e.m. } \\
\text { (replicates) }\end{array}$ \\
\hline 0 & $61 \cdot 2 \pm 15 \cdot 4^{a}$ & $36.9 \pm 12.6^{a}$ & $0 / 436$ & $0 \underset{(15)}{ \pm 0^{\mathrm{a}}}$ \\
\hline 1 & $\begin{array}{c}53 \cdot 5 \pm 26 \cdot 0^{b} \\
(10)\end{array}$ & $41 \cdot 0 \pm \frac{(6)}{8 \cdot 7^{a}}$ & $40 / 378$ & $\begin{array}{c}10 \cdot 6 \pm 5 \cdot 4^{b} \\
(13)\end{array}$ \\
\hline 2 & $39 \cdot 4 \frac{ \pm 19 \cdot 0^{c}}{(25)}$ & $37.9 \pm 10 \cdot 0^{\mathrm{a}}$ & $129 / 719$ & ${ }_{(22)}^{16 \cdot 9 \pm 9 \cdot 2^{c}}$ \\
\hline 3 & $\begin{array}{c}36 \cdot 8 \pm 18 \cdot 8^{c} \\
(11)\end{array}$ & $28 \cdot 4 \pm 11.4^{\mathrm{a}}$ & $50 / 394$ & $\begin{array}{c}10 \cdot 1 \pm 7 \cdot 7^{b} \\
\text { (11) }\end{array}$ \\
\hline 4 & $24 \cdot 4 \frac{ \pm 15 \cdot 6^{\mathrm{d}}}{(13)}$ & $40 \cdot 3 \pm 7 \cdot 7 \cdot 5^{a}$ & $27 / 319$ & $9 \cdot 4 \pm 3 \cdot 8^{b}$ \\
\hline
\end{tabular}

\footnotetext{
a,b,c,d Within columns, values with different superscripts are significantly different. The $P$ value was set at $P<0.001$ for motility, $<0.1$ for acrosome reactivity and $<0.025$ for penetration.
}

for $2 \mathrm{~h}$ penetrated $0 / 389$ eggs compared with $64 / 407$ for eggs incubated with spermatozoa preincubated at $37^{\circ} \mathrm{C}$ for $2 \mathrm{~h}(P<0.005)$. The percentage of spermatozoa that had undergone an acrosome reaction was statistically different $(P<0.05)$ between $22^{\circ} \mathrm{C}$ and $37^{\circ} \mathrm{C}(31.3 \% \pm 5.5$ versus $38 \cdot 3 \% \pm 9 \cdot 1$, respectively). Sperm motility after a $2 \mathrm{~h}$ preincubation at $22^{\circ} \mathrm{C}$ was $49 \cdot 7 \% \pm 18 \cdot 6$ and $41 \cdot 2 \% \pm 18 \cdot 4$ after $2 \mathrm{~h}$ at $37^{\circ} \mathrm{C}$.

Table 3. Effect of preincubation temperature on penetration rates of Siberian tiger spermatozoa

\begin{tabular}{|c|c|c|c|}
\hline \multirow{2}{*}{$\begin{array}{l}\text { Tiger } \\
\text { No. }\end{array}$} & \multirow{2}{*}{$\begin{array}{l}\text { No. of } \\
\text { replicates }\end{array}$} & \multicolumn{2}{|c|}{$\begin{array}{l}\text { Sperm penetration* after } \\
2 \mathrm{~h} \text { preincubation at }\end{array}$} \\
\hline & & $22^{\circ} \mathrm{C}$ & $37^{\circ} \mathrm{C}$ \\
\hline 1159 & 4 & $0 / 65(0 \%)$ & $12 / 64 \quad(18 \cdot 8 \%)$ \\
\hline 862 & 3 & $0 / 62(0 \%)$ & $13 / 60(21 \cdot 7 \%)$ \\
\hline 2832 & 3 & $0 / 97(0 \%)$ & $11 / 108(10 \cdot 2 \%)$ \\
\hline 105 & 3 & $0 / 71(0 \%)$ & $21 / 102(20 \cdot 6 \%)$ \\
\hline \multirow[t]{2}{*}{106} & 3 & $0 / 94(0 \%)$ & $7 / 73 \quad(9 \cdot 6 \%)$ \\
\hline & & 0 & $16 \cdot 2 \pm 5 \cdot 8^{* *}$ \\
\hline
\end{tabular}

*No. of ova penetrated/no. evaluated (\% penetrated).

${ }^{* *} P<0.005\left(\chi^{2}\right)$ compared with value at $22^{\circ} \mathrm{C}$.

\section{Experiment 3: effect of seminal plasma during preincubation on fresh semen}

The results indicated that capacitation could occur in the presence of seminal plasma (Fig. 1). None of the animals showed a difference $(P>0.9)$ between penetration rates of spermatozoa washed in Medium BWW (42/259) and those incubated in their seminal plasma (42/256). The percentage of spermatozoa that had undergone an acrosome reaction was not different $(P>0.05)$ between these two groups $(38 \cdot 6 \% \pm 9 \cdot 1$ versus $36 \cdot 3 \% \pm 7 \cdot 2$, respectively). 


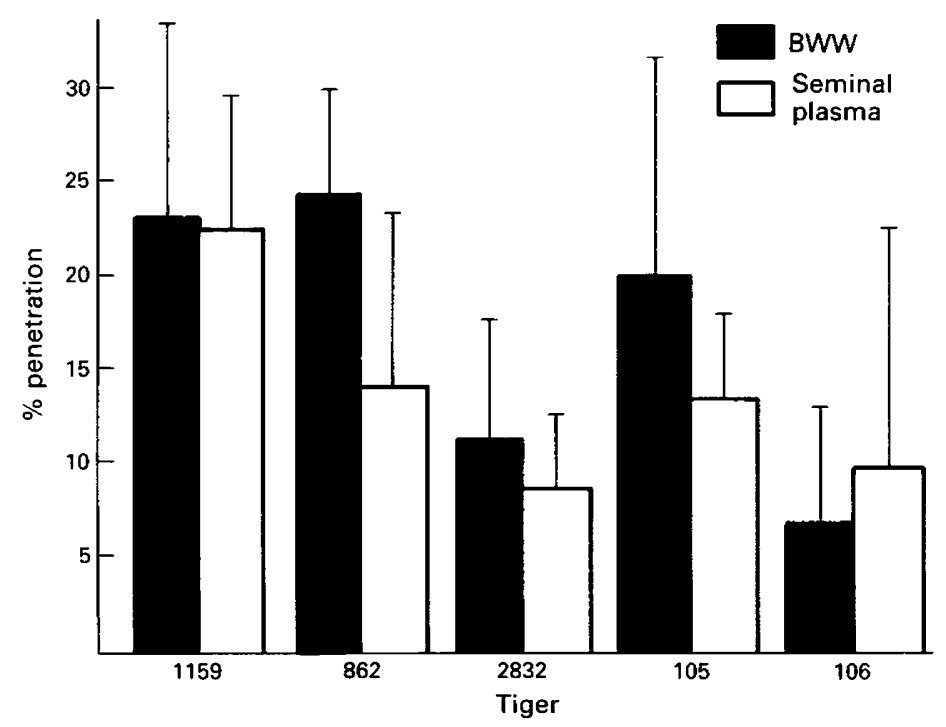

Fig. 1. Comparison of fresh penetration rates of spermatozoa from individual Siberian tigers in the presence or absence of seminal plasma. Data were based on 4 replicates per animal with a minimum of 60 oocytes evaluated per treatment. Values are means \pm s.e.m.

\section{Experiment 4: effect of preincubation time on frozen-thawed semen}

Some factor(s) of the freeze-thaw procedure resulted in a shortening of the time required for capacitation (Table 4). The $0 \mathrm{~h}$ sample penetrated $27 / 361 \mathrm{eggs}$ but none of 181 eggs were penetrated by frozen-thawed spermatozoa preincubated for $2 \mathrm{~h}(P<0.005)$. Motility decreased dramatically from $40.4 \pm 11 \cdot 3$ immediately after thawing to $6 \cdot 2 \pm 9 \cdot 2$ by $2 \mathrm{~h}$ after thawing.

Table 4. Effect of sperm preincubation time on penetration rates of frozen-thawed spermatozoa of Siberian tigers

\begin{tabular}{lccc}
\hline & & \multicolumn{2}{c}{$\begin{array}{c}\text { Sperm penetration* after } \\
\text { 2 h preincubation at }\end{array}$} \\
Tiger & $\begin{array}{c}\text { No. of } \\
\text { replicates }\end{array}$ & $0 \mathrm{~h}$ & $2 \mathrm{~h}$ \\
\hline No. & 3 & $10 / 63(15 \cdot 9)$ & $0 / 81(0)$ \\
1159 & 3 & $9 / 82(10 \cdot 9)$ & $0 / 39(0)$ \\
862 & 3 & $4 / 75(5 \cdot 3)$ & $0 / 29(0)$ \\
2832 & 2 & $2 / 89(2 \cdot 2)$ & $0 / 32(0)$ \\
105 & 2 & $2 / 52(3.8)$ & - \\
106 & & $7.6 \pm 5 \cdot 6^{* *}$ & 0 \\
& & & 0 \\
\hline
\end{tabular}

*No. of ova penetrated/no. evaluated (\% penetration). ${ }^{* *} P<0.005$ compared with value at $2 \mathrm{~h}$.

\section{Experiment 5: effect of removal of semen extender from frozen-thawed semen}

Spermatozoa had to be removed from the environment of the frozen semen extender for them to be capable of fertilization. Rate of penetration of zona-free hamster oocytes by washed spermatozoa $(18 / 159,11.32 \%)$ was significantly $(P<0.005)$ higher than that by unwashed spermatozoa $(1 / 102,0.98 \%)$. 


\section{Experiment 6: penetration rates with fresh and frozen-thawed semen}

The results of Exps 4 and 5 demonstrate that some of the frozen-thawed tiger spermatozoa had become capacitated. Table 5 illustrates that, in spite of the variation between animals in both fresh and frozen penetration rates, the overall percentage penetration was significantly higher for fresh than frozen spermatozoa. To determine whether this finding held true for individual ejaculates, several samples were split; half being assayed fresh and the remainder frozen and thawed before use in the SPA.

Table 5. Comparison of penetration of zona-free hamster eggs by fresh and frozen-thawed spermatozoa* of Siberian tigers

\begin{tabular}{lcclccc}
\hline & \multicolumn{2}{c}{ Fresh semen } & & \multicolumn{3}{c}{ Frozen semen } \\
\cline { 2 - 3 } \cline { 5 - 6 } $\begin{array}{l}\text { Tiger } \\
\text { No. }\end{array}$ & $\begin{array}{c}\text { No. of } \\
\text { replicates }\end{array}$ & $\begin{array}{c}\text { No. of ova penetrated/ } \\
\text { no. evaluated (\%) }\end{array}$ & & $\begin{array}{c}\text { No. of } \\
\text { replicates }\end{array}$ & $\begin{array}{c}\text { No. of ova penetrated/ } \\
\text { no. evaluated (\%) }\end{array}$ \\
\hline 1159 & 5 & $26 / 126(20 \cdot 6)$ & & 7 & $18 / 159(11 \cdot 3)^{* *}$ \\
862 & 4 & $23 / 95(24 \cdot 2)$ & & 3 & $9 / 82$ & $(10 \cdot 9)^{* *}$ \\
2832 & 5 & $24 / 222(10 \cdot 8)$ & & 3 & $4 / 75$ & $(5 \cdot 3)$ \\
105 & 4 & $34 / 148(22 \cdot 9)$ & & 2 & $1 / 41$ & $(2 \cdot 4)^{* *}$ \\
106 & 5 & $13 / 134(9 \cdot 7)$ & & 2 & $2 / 52$ & $(3 \cdot 8)$ \\
Total & & $120 / 725(16 \cdot 6)$ & & $34 / 409$ & $(8 \cdot 3)^{* *}$ \\
\hline
\end{tabular}

*Not necessarily from the same ejaculate.

** $P<0.05$ compared with value for fresh semen.

Table 6. Comparison of penetration rates of zonafree hamster eggs by split ejaculates (half fresh, half frozen) from Siberian tigers

\begin{tabular}{lccc}
\hline & Fresh semen & & Frozen semen \\
\cline { 2 - 3 } $\begin{array}{l}\text { Tiger } \\
\text { No. }\end{array}$ & $\begin{array}{c}\text { No. of ova penetrated/ } \\
\text { no. evaluated }(\%)\end{array}$ & $\begin{array}{c}\text { No. of ova penetrated/ } \\
\text { no. evaluated }(\%)\end{array}$ \\
\hline 2832 & $9 / 57(15 \cdot 8)$ & & $1 / 28(3 \cdot 6)^{*}$ \\
862 & $5 / 21(23 \cdot 8)$ & & $1 / 3(33 \cdot 3)^{*}$ \\
862 & $3 / 11(27 \cdot 3)$ & & $5 / 45(11 \cdot 1)^{*}$ \\
105 & $5 / 18(27 \cdot 8)$ & & $0 / 11(0)^{*}$ \\
105 & $2 / 28(7 \cdot 1)$ & & $1 / 30(3 \cdot 3)^{*}$ \\
106 & $3 / 30(10 \cdot 0)$ & & $0 / 13(0)^{*}$ \\
106 & $3 / 30(10 \cdot 0)$ & & $2 / 39(5 \cdot 1)^{*}$ \\
Total & $30 / 195(17 \cdot 4 \pm 8 \cdot 8)$ & $10 / 169(8 \cdot 1 \pm 11 \cdot 7)^{* *}$ \\
\hline
\end{tabular}

*Penetration rates are significantly different from those for fresh samples of the same ejaculate: $0.002<P<0.01$.

${ }^{* *} P<0.005$ compared with value for fresh semen.

The results for Exp. 6, using split ejaculates (Table 6), were similar to those in Table 5. The portion of the ejaculate that had been frozen and thawed before use in the SPA penetrated significantly fewer oocytes than did the fresh portion. Fitting the data with a logit model resulted in a $P$ value of $<0.005$ for the difference between fresh and frozen sperm penetration. Under our optimum conditions of 2 -h preincubation at $37^{\circ} \mathrm{C}$, the motility of fresh spermatozoa was $41 \cdot 2 \% \pm 18 \cdot 4$ at the time of coincubation with ova and that of frozen-thawed spermatozoa was $40.4 \% \pm 11 \cdot 8$ $(P>0.05)$. However, the percentage of spermatozoa that were devoid of acrosomes under these 
Table 7. Correlation coefficients for penetration of zona-free hamster oocytes $v s$ other semen parameters for Siberian tigers

\begin{tabular}{lc}
\hline Parameters & $\begin{array}{c}\text { Correlation } \\
\text { coefficient } \\
(r)\end{array}$ \\
\hline Volume & $0 \cdot 20$ \\
Concentration, $\times 10^{6}$ & $0 \cdot 36$ \\
Motility & $0 \cdot 37$ \\
Viability, \% live & $0 \cdot 16$ \\
Morphology, \% normal & $0 \cdot 38$ \\
Motility at insemination & $0 \cdot 71$ \\
\hline
\end{tabular}

conditions differed significantly $(P<0.005)$ : fresh samples preincubated for $2 \mathrm{~h}$ at $37^{\circ} \mathrm{C}$ had $38 \cdot 4 \% \pm 7 \cdot 4$ acrosome-reacted spermatozoa while $52.6 \% \pm 5.3$ of frozen-thawed spermatozoa were acrosome reacted. Whether this was due to their having undergone a true acrosome reaction or the result of a nonspecific degeneration could not be determined.

\section{Discussion}

The capacitation results of these experiments using fresh spermatozoa from 5 Siberian tigers confirm the preliminary results reported previously on one tiger (Byers et al., 1987), namely in-vitro capacitation of Siberian tiger spermatozoa requires a 2-h preincubation period at $37^{\circ} \mathrm{C}$ in capacitation medium or in seminal plasma. The decapacitation factor in the seminal plasma of several other species (rabbit: Chang, 1957; guinea-pig: Hyne \& Garbers, 1982; mouse: Fraser \& Drury, 1976; human: Reddy et al., 1979) is either not present or not functional in the electroejaculate of Siberian tigers. Howard et al. (1988) reported that removal of seminal plasma was not required for in-vitro capacitation of domestic cat spermatozoa before penetration of zona-free hamster ova. Preliminary results (unpublished) of protein analysis of tiger seminal plasma suggests a low protein content. A detailed analysis is underway which may reveal the factors which make tiger seminal plasma different from seminal plasma which blocks capacitation.

Frozen-thawed Siberian tiger spermatozoa are capable of penetrating zona-free hamster eggs although at a significantly $(P<0.05)$ lower rate than fresh spermatozoa (Table 5$)$. Part of this reduced rate of penetration might be due to reduced numbers of viable spermatozoa after thawing. While the acrosome data (Exp. 6) support that hypothesis, motility data indicate that a reasonable percentage of motile spermatozoa $(40 \cdot 4 \pm 11 \cdot 3)$ remain after thawing.

Experiment 4 demonstrates the ability of the spermatozoa to penetrate eggs immediately after thawing. Fresh tiger spermatozoa, as described above, require $2 \mathrm{~h}$ of preincubation to undergo capacitation. Therefore, some factor or factors involved in the freeze-thaw process decrease this capacitation time requirement. It may be the semen extender itself that acts as a capacitation promoter during the $3 \mathrm{hr}$ cooling period (Ijaz \& Hunter, 1988) or it may be due to the glycerol (Slavik, 1987).

The results of Exp. 5 with frozen semen indicate that removal of semen extender from thawed spermatozoa is required for penetration of zona-free hamster oocytes. Considerable ultrastructural and biochemical changes in the acrosome occur after glycerol cryopreservation (Mahadevan \& Trounson, 1984; Heath et al., 1985). It is also possible that glycerol and/or egg yolk proteins in the extender are interfering with sperm-egg interactions by blocking binding sites on the postacrosomal segment. The finding that frozen-thawed tiger spermatozoa are capable of fertilization provides the incentive for further research in artificial insemination in this species. The decrease in penetration rates of frozen-thawed spermatozoa compared with fresh spermatozoa (Tables $5 \& 6$ ) 
was not surprising. However, by adjusting the freeze-thaw protocol it may be possible to increase the fertilizing capacity of these sperm cells.

The preservation of Siberian tigers, as well as the other 36 species of felids whose continued existence in the wild is threatened, has become the responsibility of captive breeding programmes. This is a difficult task since much of the basic physiology of these exotic species is not yet fully understood. This study provides valuable basic information of male tiger reproductive physiology. The use of the hamster egg-sperm penetration assay defines the conditions required for in-vitro capacitation of fresh and frozen spermatozoa of Siberian tigers. The SPA appears to measure a functional capacity of the sperm cell which is not revealed by routine semen analysis. The correlation coefficients for tiger sperm penetration into hamster eggs versus semen analysis parameters are given in Table 7. None of these correlation coefficients is large enough to be used as a prediction of penetration. Although the value of 0.71 for the correlation between penetration and motility at insemination is relatively large, $r^{2}$ is 0.50 . This means that only $50 \%$ of the time can the variability in penetration be attributed to motility at insemination. Similar values have been reported correlating human sperm penetration of zona-free hamster ova with sperm concentration $(r=0 \cdot 29)$ and motility $(r=0.33)$ (Cohen et al., 1982). Our conclusion that the SPA provides important information about the fertility of tiger spermatozoa is in agreement with the findings of several other investigators working with semen of various species (Yanagimachi, 1984).

Financial support was provided by the Minnesota Zoological Garden, the Veteran's Administration Research Service and the University of Minnesota Agricultural Experiment Station Project 72.

We thank Como Zoo director V. Camp; staff veterinarian, Dr Ralph Farnsworth; and the keepers at both the Minnesota and Como Zoos for their co-operation; and M. A. Seal, M. Schmehl, Rita Deyo and Debra Berg for valuable assistance.

\section{References}

Austin, C.R. (1952) The 'capacitation' of the mammalian sperm. Nature, Lond. 170, 326.

Biggers, J.D., Whitten, W. K. \& Whittingham, D.G. (1971) The culture of mouse embryos in vitro. In Methods in Mammalian Embryology, pp. 86-116. Ed. J. C. Daniel. Freeman \& Co., San Francisco.

Bowen, R.A. (1977) Fertilization in vitro of feline ova by spermatozoa from the ductus deferens. Biol. Reprod. 17, $144-147$.

Byers, A.P., Hunter, A.G., Hensleigh, H.C., Kreeger, T.J., Binczik, G., Reindl, N.L., Seal, U.S. \& Tilson, R.T. (1987) In vitro capacitation of Siberian tiger spermatozoa. Zoo Biology 6, 297-304.

Chang, M.C. (1957) A detrimental effect of seminal plasma on the fertilizing capacity of sperm. Nature, Lond. 179, 258-259.

Cohen, J., Mooyaart, M., Vreeburg, J.T.M. \& Zeilmaker, G.H. (1982) Fertilization of hamster ova by human spermatozoa in relation to other semen parameters. Int. J. Androl. 5, 210-224.

Fraser, L.R. \& Drury, L.M. (1976) Effect of removal of epididymal secretions on fertilization in vitro of mouse eggs. J. Reprod. Fert. 48, 125-128.

Graham, E.F., Crabo, B.G. \& Brown, K.I. (1972) Effect of some zwitter ion buffers on the freezing and storage of spermatozoa. I. Bull. J. Dairy Sci. 55, 372-378.

Hamner, C.E., Jennings, L.L. \& Sojka, N.J. (1970) Cat (Felis catus L.) spermatozoa require capacitation. $J$. Reprod. Fert. 23, 477-480.
Heath, E., Jeyendran, R.S., Perez-Palaez, M. \& Sobrero, A.J. (1985) Ultrastructural categorization of human sperm cryopreserved in glycerol and TESTCY. Int. $J$. Androl. 8, 101-110.

Howard, J.G., Bush, M., deVos, V. \& Wildt, D.E. (1984a) Electroejaculation, semen characteristics and serum testosterone concentrations of free-ranging African elephants (Loxodonta africana). J. Reprod. Fert. 72, 187-195.

Howard, J.G., Bush, M., Simmons, L.G. \& Wildt, D.E. (1984b) Comparative characteristics in nondomestic felids with emphasis on sperm morphology. Proc. Am. Assoc. Zoo Veterinarians, Louisville pp. 168-170.

Howard, J.G., Barone, M.A., Clingerman, K.J., Bush, M. \& Wildt, D.E. (1988) Influence of teratospermia, culture media and a sperm swim-up technique on penetration of zona-free hamster ova by domestic cat spermatozoa. Proc. 11th Int. Congr. Anim. Reprod. \& A.I., Dublin, vol. 3, p. 332, Abstr.

Hyne, R.V. \& Garbers, D.L. (1982) Inhibition of the guinea-pig acrosome reaction by a low molecular weight factor(s) in epididymal filuid and serum. $J$. Reprod. Fert. 64, 151-157.

Ijaz, A. \& Hunter, A.G. (1988) Effect of buffers containing Tes and/or tris on bovine sperm motility and their ability to penetrate zona-free hamster oocytes. Biol. Reprod. 38 (Suppl. 1), 97, abstr.

Lenz, R.W., Ball, G.D., Lohse, J.K., First, N.L. \& Ax, R.L. (1983) Chondroitin sulphate facilitates an acro- 
some reaction in bovine spermatozoa as evidenced by light microscopy, electron microscopy and in vitro fertilization. Biol. Reprod. 28, 683-690.

Mahadevan, M.M. \& Trounson, A.O. (1984) Relationship of fine structure of sperm head to fertility of frozen human sperm. Fert. Steril. 41, 287-293.

Niwa, K., Ohara, K., Hosoi, Y. \& Iritani, A. (1985) Early events of in-vitro fertilization of cat eggs by epididymal spermatozoa. J. Reprod. Fert. 75, 657-660.

Reddy, J.M., Stark, R.A. \& Zaneveld, L.J.D. (1979) A high molecular weight antifertility factor from human seminal plasma. J. Reprod. Fert. 57, 437-446.

Rogers, B.J., Van Campen, H., Ulno, M., Lambert, H., Bronson, R. \& Hale, R. (1979) Analysis of human spermatozoal fertilizing ability using zona-free ova. Fert. Steril. 32, 664-670.

Seal, U.S. \& Foose, T. (1983) Species survival plan for Siberian tigers in North American zoos: a strategy for survival. Proc. Am. Assoc. Zoo Veterinarians, Tampa pp. $33-40$.

Slavik, T. (1987) Effect of glycerol on the penetrating ability of fresh ram spermatozoa with zona-free hamster eggs. J. Reprod. Fert. 79, 99-103.

Swanson, E.W. \& Bearden, H.J. (1951) An eosin-nigrosin stain for differentiating live and dead bovine spermatozoa. J. Anim. Sci. 10, 981-987.

Yanagimachi, R. (1984) Zona-free hamster eggs: their use in assessing fertilizing capacity and examining chromosomes of human spermatozoa. Gamete Res. 10, 187-232.

Yanagimachi, R., Yanagimachi, H. \& Rogers, B.J. (1976) The use of zona-free animal ova as a test-system of the fertilizing capacity of human spermatozoa. Biol. Reprod. 15, 471-476.

Received 31 October 1988 